\title{
Antibiotic resistant fever associated with herpes simplex virus infection in neutropenic patients with haematological malignancy
}

\author{
T P BAGLIN, * J J GRAY, R E MARCUS, * T G WREGHITT \\ From the Department of ${ }^{*}$ Haematology and the Clinical Microbiology and Public Health Laboratory, \\ Addenbrooke's Hospital, Cambridge
}

SUMMARY The incidence of mucocutaneous herpes simplex virus infection confirmed by culture and occurring during febrile neutropenic episodes was determined in 43 patients with haematological malignancy. The outcome of 72 episodes of neutropenic fever was determined and correlated with the presence or absence of herpes simplex virus (HSV) infection. Twenty four patients had mucocutaneous HSV infection during at least one episode. In 24 episodes in which HSV was isolated only $12.5 \%$ of fevers responded to antibiotics and $75 \%$ of fevers were otherwise unexplained. Conversely, in 48 episodes of neutropenic fever in which HSV was not isolated $67 \%$ of fevers responded to antibiotics and only $8 \cdot 3 \%$ were unexplained. The difference in incidence of antibiotic resistant fever in the two groups was significant. There was, therefore, a strong association between mucocutaneous HSV infection and antibiotic resistant fever in immunosuppressed neutropenic patients. As most HSV infections are the result of virus reactivation, establishing the HSV serological state of patients would identify those at risk of infection and hence those in whom the prophylactic use of acyclovir would be indicated.

Early treatment with broad spectrum bactericidal antibiotics reduces the morbidity and mortality from bacterial infection in neutropenic patients. ${ }^{1-4} \mathrm{~A}$ significant proportion of febrile episodes which occur in neutropenic patients, however, fail to respond to broad spectrum antibiotics. ${ }^{1-4}$ In these cases antibiotic resistant bacteria and invasive fungal and viral infections are sometimes identified. ${ }^{4}$ Reactivation of herpes simplex virus (HSV) is increasingly recognised in patients with haematological malignancy, ${ }^{56}$ and mucocutaneous infection is a major cause of morbidity in patients after bone marrow transplantation. ${ }^{78}$ An association between $\mathrm{HSV}$ infection and prolonged fever in recipients of allogeneic bone marrow transplants has been suggested, ${ }^{8}$ but HSV infection as a cause of persistent fever in neutropenic patients has not been confirmed. We therefore set out to determine the incidence of HSV infection in patients with haematological malignancy who were receiving intensive chemotherapy and to correlate this with the outcome of episodes of neutropenic fever.

\section{Patients and methods}

The records of febrile neutropenic patients in whom throat swabs for virus culture had been taken at the onset of fever were examined for details of infection, fever, bacterial isolates and response to antibiotics.

Neutropenic fever was defined as a single recording of $39^{\circ} \mathrm{C}$ or greater, or two recordings of $38^{\circ} \mathrm{C}$ two hours apart in a patient with a neutrophil count of less than $0.5 \times 10^{9} / 1$. Patients were examined for clinical signs of infection, and blood cultures were taken from a peripheral vein and central line if present. Throat and rectal swabs were taken for bacterial culture, and a throat swab in virus transport medium for virus culture was taken from all patients. Patients were then treated with parenteral antibiotics: piperacillin $4 \mathrm{~g}$ and gentamicin $80 \mathrm{mg}$ four times a day each, and then appropriate antibiotics as indicated by bacterial isolates. If fever had not settled within 48 hours and bacterial cultures were negative, ceftazadime $2 \mathrm{~g}$ three times a day and vancomycin $500 \mathrm{mg}$ twice a day were given and the response noted 48 to 72 hours later. Patients known to be allergic to penicillin were treated initially with ceftazadime and gentamicin. Patients not responding to two combinations of broad spectrum 
antibiotics were considered to have antibiotic resistant fever. This definition of resistant fever excluded patients with intermittent fever associated with administration of blood products.

For the isolation of virus, swabs were collected in virus transport medium ( $2 \mathrm{ml}$ Hanks's balanced salt solution with $1 \%$ bovine albumin). A volume of $100 \mu \mathrm{l}$ was inoculated into cultures of human amnion, Vero, or MRC-5 cells which were then rolled for seven to 10 days at $37^{\circ} \mathrm{C}$. Those cultures showing a cytopathic effect characteristic of HSV were stored at $-20^{\circ} \mathrm{C}$. Serotyping of HSV was performed with the Imagen HSV direct immunofluorescence assay (Celltech Diagnostics Ltd).

Data were analysed by Fischer's exact test and the Mann-Whitney U test.

\section{Results}

INCIDENCE OF HER PES SIMPLEX VIRUS INFECTION One hundred and sixty one throat swabs were taken during 72 episodes of neutropenic fever occurring in 43 patients. The diagnoses and the number of patients with at least one episode of HSV infection confirmed by culture are shown in table 1 .

Cultures from 13 swabs were discarded because of contamination with either bacteria or fungi. Of the remaining 148 swabs, HSV was cultured from $52(32 \%$ of all swabs). Positive HSV cultures were obtained during 24 episodes of neutropenic fever (mean number of positive swabs for each HSV infection $=2 \cdot 2$ ). In all cases patients were also lymphopenic $\left(<1.0 \times 10^{9} / 1\right)$. There was no correlation, however, between the incidence of HSV infection and the absolute lymphocyte count. Furthermore, there was no difference in lymphocyte counts at the time of infection in those patients with HSV $\left(0.4 \times 10^{9} / 1\right)$ and those without HSV infection $\left(0.5 \times 10^{9} / 1\right)(\mathrm{p}=$ NS by Mann-

Table 1 Diagnoses and number of patients with at least one episode of HSV infection confirmed by culture

\begin{tabular}{|c|c|c|}
\hline Diagnosis & $\begin{array}{l}\text { No of } \\
\text { patients }\end{array}$ & $\begin{array}{l}\text { No of } \\
\text { patients with } \\
\text { HSV infection }\end{array}$ \\
\hline $\begin{array}{l}\text { Myeloid malignancies: } \\
\text { Acute myeloblastic leukaemia } \\
\text { Chronic myeloid leukaemia } \\
\text { Aplastic anaemia }\end{array}$ & $\begin{array}{r}14 \\
2 \\
1\end{array}$ & $\begin{array}{l}6 \\
0 \\
1\end{array}$ \\
\hline $\begin{array}{l}\text { Lymphoid malignancies: } \\
\text { Acute lymphoblastic leukaemia } \\
\text { High grade non-Hodgkin's } \\
\text { lymphoma } \\
\text { Chronic lymphocytic leukaemia } \\
\text { Hairy cell leukaemia } \\
\text { Myeloma }\end{array}$ & $\begin{array}{r}4 \\
10 \\
1 \\
1 \\
4\end{array}$ & $\begin{array}{l}3 \\
9 \\
0 \\
0 \\
1\end{array}$ \\
\hline $\begin{array}{l}\text { Others: } \\
\text { Hodgkin's disease } \\
\text { Totals }\end{array}$ & $\begin{array}{r}6 \\
43\end{array}$ & $\begin{array}{r}4 \\
24\end{array}$ \\
\hline
\end{tabular}

Whitney test). All HSV strains were serotyped as HSV type 1 .

The same 43 patients had a further 152 surveillance 음 throat swabs cultured for HSV when not febrile. Only 15 swabs from six patients grew HSV. None of the patients was febrile or neutropenic at the time swabs were taken, all but one were lymphopenic $(<1.0 \times$ $\left.10^{9} / 1\right)$. These episodes were not associated with recent $\frac{\bar{m}}{\frac{}{\sigma}}$ chemotherapy, five occurring in patients with active $\stackrel{\mathbb{Q}}{\propto}$ lymphoma and one following anti-lymphocyte globu- के lin treatment for aplastic anaemia.

\section{RESPONSE OF NEUTROPENIC FEVER TO \\ ANTIBACTERIAL TREATMENT AND RELATION TO \\ HSV INFECTION}

Seventy two episodes of neutropenic fever were recorded. HSV was isolated at the time of fever in $24 \stackrel{N}{-}$ episodes (33\%) and was not cultured in $48(67 \%)$. One $\vec{N}$ patient in each group died, giving an overall mortality of $3 \%$.

Only three $(12.5 \%)$ of the 24 febrile neutropenic ㅇ episodes in which HSV was cultured responded to antibacterial treatment. Positive blood cultures were obtained on six occasions. On two occasions bacteria were resistant to the antibiotics administered. A single episode of fever responded to removal of an indwelling central venous catheter. One case of aspergillus, diagnosed serologically, was documented but intra venous amphotericin did not lead to resolution of the fever. Eighteen episodes (75\%) of persistent fever wers unexplained, apart from the presence of mucocutaneous HSV infection. Symptoms or signs suggestive of mucocutaneous HSV infection were recorded in only six of the 24 episodes.

In contrast, in $32(67 \%)$ of the 48 episodes in which HSV was not isolated fever responded to either first or second line antibacterial treatment. Positive blood

Table 2 Outcome of 72 episodes of neutropenic fever with respect to results of $\mathrm{HSV}$ cultures

\begin{tabular}{lll}
\hline & No of episodes & \\
\cline { 2 - 3 } & $\begin{array}{l}\text { Negative } \\
\text { HSV culture }\end{array}$ & $\begin{array}{l}\text { Positive } \\
\text { HSV culture }\end{array}$ \\
\hline $\begin{array}{l}\text { Outcome of neutropenic fever } \\
\begin{array}{l}\text { Response to antibacterial } \\
\text { treatment }\end{array}\end{array}$ & 32 & 3 \\
$\begin{array}{l}\text { Resistant bacteria } \\
\text { Response to removal of central } \\
\text { venous catheter }\end{array}$ & 2 & 2 \\
$\begin{array}{l}\text { Response to granulocyte } \\
\text { transfusion }\end{array}$ & 2 & 1 \\
$\begin{array}{l}\text { Response to surgical drainage } \\
\text { of abcess }\end{array}$ & 1 & - \\
$\begin{array}{l}\text { Culture confirmation or } \\
\text { seroconversion to aspergillus } \\
\text { and response to amphotericin }\end{array}$ & 4 & - \\
$\begin{array}{l}\text { Confirmed by culture candida } \\
\text { hepatitis }\end{array}$ & 2 & - \\
$\begin{array}{l}\text { Unexplained fever } \\
\text { Total }\end{array}$ & 1 & 18 \\
\hline
\end{tabular}


cultures were obtained in 11 of the 48 episodes. In two the bacteria were resistant to the antibiotics administered. An identifiable cause of fever was found in a further 12 episodes (table 2). Four (8.3\%) cases of unexplained fever remained.

In the presence of mucocutaneous HSV infection confirmed by culture $75 \%$ of neutropenic fevers either failed to respond to appropriate antibacterial treatment or remained unexplained, compared with only $8.3 \%$ in the absence of HSV infection ( $p<0.001$, Fischer's exact test).

\section{Discussion}

Bacterial infection in neutropenic patients may be rapidly fatal, and as the results of bacterial cultures and hence antibiotic sensitivities are not immediately available patients are treated empirically with parenteral broad spectrum antibiotics. This approach has greatly reduced the mortality associated with episodes of neutropenic fever..$^{1-4}$ The mortality during neutropenic fever in our study was $3 \%$ and the incidence of documented bacteraemia was $24 \%$, both of which are comparable with the data of previous studies. $^{1-4}$

Herpes virus infections are common in immunosuppressed patients. ${ }^{5-10}$ The rate of HSV reactivation in patients with high grade lymphoproliferative malignancy has been reported to be as high as $60 \%,{ }^{11}$ while a prospective point prevalence study in 29 patients with acute myeloblastic leukaemia showed a $34.5 \% \mathrm{HSV}$ reactivation rate, with $40 \%$ of patients shedding HSV on at least one occasion. ${ }^{6}$ In our study $52 \%$ of patients with haematological malignancy had at least one documented episode of HSV infection during episodes of neutropenic fever.

Our data suggest that in patients at risk of reactivation of HSV, infection is associated with lymphopenia rather than neutropenia. This observation is in keeping with known mechanisms of $T$ cell mediated defence against HSV.' Among the lymphoid malignancies there were only two $\mathrm{T}$ cell high grade lymphomas and two cases of $T$ cell acute lymphoblastic leukaemia. Most HSV infections, therefore, occurred in patients with $B$ cell lymphomas. We suggest that this is because active HSV infection is associated with the severe lymphopenia associated with intensive chemotherapy rather than impairment of lymphocyte function associated with disease. As all the patients in this study were lymphopenic at times of neutropenia, neutropenic patients seem to be at risk of HSV infection by virtue of associated lymphopenia. Notably, fever was only associated with HSV infection in our patients when they were lymphopenic and neutropenic following intensive cytotoxic chemotherapy. At this time the integrity of mucous mem- branes is also compromised and this may allow a portal of entry for organisms, particularly Gram positive bacteria. ${ }^{1213}$

The high incidence of antibiotic resistant fever in neutropenic patients with HSV infection $(87.5 \%)$, compared with those without $(33 \%, p<0.001)$ indicates the importance of recognising HSV infection as a contributory factor in persistent fever in neutropenic patients. Symptoms or signs suggestive of HSV infection, such as mouth ulceration, gingivitis, sore throat and oesophagitis were not documented in $70 \%$ of cases confirmed by culture. Undue reliance should not be placed, therefore, on the clinical findings alone.

Although the incidence of disseminated HSV infection is low, the prophylactic administration of acyclovir to HSV antibody positive patients during neutropenia might reduce not only morbidity, related to mucosal ulceration, but also the incidence of antibiotic resistant fever. This study did not prospectively evaluate the response of fever to the therapeutic administration of acyclovir. In several prospective controlled studies, however, acyclovir has been shown to be effective in preventing HSV infection in patients with haematological malignancy. The pharmacokinetics of absorption of orally administered acyclovir do not seem to be significantly affected by gut toxicity, ${ }^{14}$ and both oral ${ }^{711} 14$ and intravenous ${ }^{815}$ prophylaxis with acyclovir are effective. Furthermore, significant resistance to acyclovir has not been found in our patients, despite altered susceptibility to acyclovir during treatment of established HSV infection, and oral therapy should be adequate in most if not all patients. ${ }^{16}$

In conclusion, mucocutaneous HSV infection in immunosuppressed neutropenic patients is associated with antibiotic resistant fever. There is therefore a rational basis for the inclusion of acyclovir in the management of fever in these patients and its use may reduce that of intravenous amphotericin $B$ and second line antibiotics. Because HSV infection is predominantly the result of virus reactivation, establishing the HSV seropositive state of patients would identify those at risk of infection and hence those in whom prophylaxis with acyclovir would be indicated.

We are grateful to the Clinical Microbiology and Public Health Laboratory, Addenbrooke's Hospital, for bacterial culture and antibiotic sensitivity testing; Dr R Warren for reviewing the manuscript and much helpful advice; Mrs P Warren for coordinating sample collections, and Mrs C A Baglin for preparing the manuscript.

\section{References}

1 The EORTC International Antimicrobial Therapy Project Group. Three antibiotic regimens in the treatment of infection in febrile 
granulocytopenic patients with cancer. J Infect Dis 1978;137: 14-29.

2 Klastersky J, Glauser MP, Scimpff SC, Zinner SH, Gaya H. European Organisation for Research on Treatment of Cancer Antimicrobial Therapy Project Group. Prospective randomised comparison of three antibiotic regimens for empirical therapy of suspected bacteraemic infection in febrile granulocytopenic patients. Antimicrob Agents Chemother 1986;29:263-70.

3 The EORTC International Antimicrobial Therapy Cooperative Group. Ceftazidime combined with a short or long course of Amikacin for empirical therapy of gram-negative bacteraemia in cancer patients with granulocytopenia. $N$ Engl J Med 1987: 1692-8.

4 Gaya $H$. Rational basis for the choice of regimens for empirical therapy of sepsis in granulocytopenic patients. Clin Haematol 1984:13:573-86.

5 Muller SA, Hermann EC, Winklemann RK. Herpes simplex infections in haematological malignancies. Am J Med 1972;52: $102-14$.

6 Lam MT, Pazin GJ, Armstrong JA, Monto HO. Herpes simplex infection in acute myelogenous leukemia and other hematologic malignancies: A prospective study. Cancer 1981;48:2168-71.

7 Wade JC, Newton B, McLaren C, Flournoy N, Keeney RE, Meyers JD. Intravenous acyclovir to treat mucocutaneous herpes simplex virus infection after marrow transplantation. Ann Intern Med 1982;96:265-9.

8 Hann IM, Prentice HG, Blacklock HA, et al. Acyclovir prophylaxis against herpes virus infections in severely immunocompromised patients: randomised double blind trial. $\mathrm{Br} \mathrm{Med} \mathrm{J}$ 1983;287:384-8.

9 Rand KH, Rasmussen LE, Pollard RB, Arvin A, Merigan TC Cellular immunity and herpes virus infections in cardiac transplant patients. $N$ Engl J Med 1977;296:1372-7.

10 Crosby DL, Jones JH, Sussman M. Herpetic naso-oral ulcers after renal transplantation. Lancet 1969;ii: 1191.

11 Anderson H, Scarffe JH, Sutton RNP, Hickmott E, Brigden D, Burke C. Oral acyclovir prophylaxis against herpes simplex virus in non-Hodgkin lymphoma and acute lymphoblastic leukaemia patients receiving remission induction chemotherapy. A randomised double blind, placebo controlled trial. Br J Cancer 1984;50:45-9.

12 Cohen J, Worsley AM, Goldman JM, Donnelly JP, Catovsky D, Galton DAG. Septicaemia caused by viridans streptococci in neutropenic patients with leukaemia. Lancet 1983;ii:1452-4.

13 Ringden O, Heimdahl A, Lonnqvist B, Malmborg A, Wiczek H. Decreased incidence of viridans streptococcal septicaemia in allogeneic bone marrow transplant recipients after the introduction of acyclovir. Lancet 1984;i:744.

14 Gluckman E, Lotsberg J, Devergie A, et al. Prophylaxis of herpes infections after bone marrow transplantation by oral acyclovir. Lancet 1983;ii:706-8.

15 Saral R, Ambinder RF, Burns WH, et al. Acyclovir prophylaxis against herpes simplex virus infection in patients with leukaemia - a randomised, double-blind, placebo-controlled study. Ann Intern Med 1983;99:773-6.

16 Gray JJ, Wreghitt TG, Baglin TP. Susceptibility to acyclovir of herpes simplex virus isolated from patients in Cambridge, UK: Emergence of resistant strains in patients with haematological malignancy. J Infect 1989;19:31-40.

Requests for reprints to: Dr T P Baglin, Department of Haematology, Addenbrooke's Hospital, Hills Road, Cambridge CB2 2QQ, England. 